right knee. When admitted into hospital on Jan. 20th, 1903, the heart on percussion was a good deal enlarged; on auscultation systolic and diastolic murmurs were heard at the apex. The diastolic murmur was localised; the systolic murmur was conducted to the anterior axillary line, while the first sound was heard at the scapular angle. At the pulmonary area there was a localised, harsh systolic murmur which was best heard at the inspiratory acme (? exocardial). The liver was much enlarged and tender and its surface was granular, there being a distinct hepatic pulsation. The patient had no clubbing of the fingers and only some "back-pressure" cyanosis, as is usual in the later stages of mitral disease. The pulse was regular, of good tension, ranging from 70 to 80 , and occasionally bigeminal. She remained in much the same state and died quite suddenly on May 11th. At the postmortem examination the hypertrophied and dilated right and left auricles were found to communicate by a patent, almost round, foramen ovale two inches in diameter. The mitral valve showed old fibrous stenosis, barely admitting two finger tips, while the tricuspid valve admitted seven finger-tips. The left ventricle was somewhat hypertrophied. The aortic and pulmonary valves were normal. The heart weighed 22 ounces; its consistency was flabby and its apex was rounded.

CASE 2.-The patient was a married woman, aged 39 years. She complained of dyspncea, general cedema, and palpitation. There was no previous rheumatic history, but she had had "twitchings" daring her last pregnancy a year previously. There had been palpitation with cardiac irregularity for the last 15 years, but worse during the last two years-i.e, since her second confinement. She had been admitted to hospital twice this year, the last time being on April 30th, when she had rheumati-m in the legs and arms, well-marked dyspnœa, and præcordial pain. The cardiac dulness was much increased from side to side. At the apex a presystolic murmur was heard with an accentuated first sound and a feeble second sound. The liver was enlarged and tender and it pulsated distinctly. There was some cdema in the lumbar region. The pulse ranged from 80 to 100 ; it was of low tension, feeble, and regular. In a day or two she developed signs and symptoms of pericarditis with effusion, the upward dulness reaching the second rib. She never had any clubbing of the fingers and (except very slight of the lips) never had any cyanosis. The patient slowly got weaker and died on May 17th. At the postmortem examination the inter-auricular septum was found to be absent except a remnant which remained as a pillar on the anterior wall. It is interesting to note here that there was a small congenital perforation of the nasal septum just above the columella. The heart, when removed with the pericardium and large vessels, weighed 37 ounces. The apex was rounded and the consistency was fairly good. The right auricle had hypertrophied walls and was full of ante-mortem clot continuous with that in the left auricle, which was enlarged and its walls were thickened. The tricuspid valve admitted five finger tips. The pulmonary valve was wide and the aorta was distinctly narrower than the pulmonary artery. The right ventricle was much hypertrophied and dilated and contained ante-mortem c'ot. The mitral valve showed old fibrous stenosis. There was a sero-fibrinous pericarditis, chiefly recent, with a good deal of effusion.

Clinically these two cases were typical ones of mitral stenosis, in the second case with pericarditis added later. The post-mortem surprise in each case shows how long life may be prolonged in this variety of congenital heart defect, the ages of these patients being 43 and 39 years respectively; while in neither case did any symptoms suggest the existence of the defects. Here, then, are two cases of auricular septal defect, both uncomplicated by pulmonary stenosis, and both allowing, though not compelling, free mixture of venous with arterial blood, and in neither case did typical cyanosis and clubbing occur. Dr. T. Wardrop Griffith has lately discussed ${ }^{3}$ the cause of cyanosis associated with congenital heart defects. There is some causative factor of cyanosis lacking in both these cases : it appears to be pulmonary stenosis, but if so, Variot's case of stenosis without cyanosis remains inexplicable unless, as Dr. Griffith says, possibly the bronchial arteries were much enlarged and mal-aeration thus prevented. In both the present cases the ductus arteriosus was impervious, while in Case 2 the aorta

1 Medical Chronicle, Mareh, 1903. was somewhat narrow relatively to the pulmonary artery, so that in this case some blood probably passed back to the right auricle and from the right ventricle to the lungs a second time. The starting point in the cause of cyanosis in congenital heart disease seems in all cases to be pulmonary stenosis, while consequent on this follow, where septal defect is associated, compulsory mixture of venous with arterial blood, mal-aeration, and also erythrocytosis, due, just as in dwellers in high altitudes, to a deficiency of oxygen. If enlargement of the bronchial arteries prevents mal-aeraticn the chain is probably broken.

Macclesfield.

\section{TUBERCULOSIS AND CANCER IN NEW ZEALAND. ${ }^{1}$}

BY W. J. BAROLAY, M.D., F.R.O.S. EDIN., D.P.H.

THE following statistical study attempts to demonstrate several interesting facts. To anticipate, the chief conclusion is that whilst the death-rate from tuberculosis is much less in New Zealand than in England and Wales the death-rate from cancer is practically the same in both countries.

\section{A.-Tuberculosis.}

TABLE I.-Showing the Death-rates per 10,000 Persons of all Tuberculous Diseases and Pulmonary Tuberoulosis respectively is New Zealand and in England and Wales.*

\begin{tabular}{l|c|c|c|c}
\hline Year. & $\overbrace{\begin{array}{c}\text { New } \\
\text { Zealand. }\end{array}}^{\text {All tuberculous diseases. }}$ & $\begin{array}{c}\text { England and } \\
\text { Wales. }\end{array}$ & $\overbrace{\begin{array}{c}\text { New } \\
\text { Zealand. }\end{array}}^{\text {Pulmonary tuberculosis. }}$ \\
\hline 1891 & 10.53 & 23.00 & 7.86 & 15.99 \\
1892 & 10.90 & 21.35 & 8.16 & 14.67 \\
1893 & 11.02 & 21.40 & 8.24 & 14.65 \\
1894 & 11.07 & 19.67 & 8.48 & 13.81 \\
1895 & 10.99 & 20.55 & 7.99 & 13.93 \\
1896 & 9.62 & 18.83 & $7 \cdot 40$ & 13.01 \\
1897 & 10.57 & 19.22 & 8.26 & 13.35 \\
1898 & 10.44 & 19.07 & 8.11 & 13.10 \\
1899 & 10.60 & 19.01 & 7.91 & 13.29 \\
1900 & 9.85 & 18.99 & 7.56 & 13.32
\end{tabular}

* The English rates are those given by the Registrar-General; the New Zealand rates $I$ have calculated from the official death returns.

For convenience the figures in Table $I$. have been. summarised, with the addition of separate death-rates from pulmonary tuberculosis for males and for females (see Table II.).

TABLE II.-Showing the Mean Annual Death-rates per 10.000 Persons of all Tuberculous Iiseases and Pulmonary Tuberculnsis respectively in New Zealand and in England and Wales during the Ten Years 1891-1900.

$\overbrace{10.55}^{\begin{array}{c}\text { All tuberculous } \\ \text { diseases. } \\ \text { Persons. }\end{array}} \overbrace{2}^{\text {Persons. }} \overbrace{20.10}^{\text {Pulmonary tuberculosis. }}$

From Tables I. and II. it is evident (1) that the deathrate from tuberculons diseases is much less in New Zealand than in England and Wales; (2) that the death-rate from pulmonary tuberculosis is higher for males than for females in both countries; and (3) that the death-rate from tuberculous diseases is decreasing. Let us briefly consider each of these conclusions.

1. Lowness of the death-rate from tuberculosis in Nero Zealand. - The New Zealand rate is only about one-half of

1 Abstracted from a thesis submitted for the degrse of Doctor of Medicine of the University of Edinburgh. 
the English rate. This, too, in spite of the fact that pulmonary consumption is a disease especially of young adults, of whom the New Zealand population contains an excess ; in spite, also, of the fact that there is in New Zealand a relative deficiency of females, for whom the death-rate from pulmonary consumption is lower than for males; and in spite, further, of the fact that a number of consumptive patients are continually arriving in New Zealand, attracted thither by the hope of cure. For each of these three reasons the death-rate from tuberculosis in New Zealand is abnormally raised, as compared with the rate in England and Wales. What, then, is the cause of this extremely low death-rate from tuberculosis in New Zealand? There are several causes, of which the most important are that in New Zealand the climate is temperate and equable, that a great proportion of the population follow outdoor occupations, that the ill effects of factory life and of unhealthy trades are seldom seen, and that the average inhabitant enjoys good and abundant food with suitable clothing and house accommodation.

2. The death-rate from phthisis is higher for males than for females both in New Zealand and in England. - The reason of this is usually supposed to be that a greater number of males are working under unhealthy conditions- $i \mathrm{e}$, in factories, and especially those where much dust is produced. It is an additional proof of the accuracy of this explanation that in New Zealand where factory life is less common the excess of the male death-rate from tuberculosis over the female rate is much less marked than in England and Wales (see Table II.).

3. The death-rate from tuberoulosis is deoreasing in New Zealand as in Fingland and in most other countries.-Two reasons for this may be alleged : first, the improved physical condition of the people from better and cheaper food and clothing; and second, the lessened chance of infection owing to the fact that tuberculosis in particular is more and more recognised as an infectious disease spread from one patient to another unless due precautions are taken. As the importance of preventing such infection is becoming more widely known it may be expected that in all countries the death-rate will continue to fall and that even the present extremely low death-rate from tuberculosis in New Zealand will be still further reduced.

\section{B.-CANCER.}

TABLE III-Showing the Death-rates from Canoer per 10000 of the Population in New Zealand and in England and Wales respectively from 1886 to 1900.

\begin{tabular}{|c|c|c|c|c|c|c|}
\hline \multirow{2}{*}{ Year. } & \multicolumn{3}{|c|}{ New Zealand. } & \multicolumn{3}{|c|}{ England and Wales. } \\
\hline & Persons. & Males. & Females. & Persons. & Males. & $\mathrm{Females}$ \\
\hline 1886 & $3 \cdot 68$ & $3 \cdot 69$ & 367 & $5 \cdot 90$ & $4 \cdot 31$ & $7 \cdot 41$ \\
\hline 1890 & - & 472 & $4 \cdot 79$ & $6 \cdot 76$ & $5 \cdot 12$ & $8 \cdot 30$ \\
\hline 1891 & 468 & $4 \cdot 60$ & $4 \cdot 77$ & $6 \cdot 92$ & $5 \cdot 17$ & 8.55 \\
\hline 1892 & $4 \cdot 78$ & $5 \cdot 07$ & $4 \cdot 44$ & 6.89 & $5 \cdot 28$ & 8.41 \\
\hline 1893 & $5 \cdot 02$ & $5 \cdot 35$ & $4 \cdot 64$ & $7 \cdot 09$ & $5 \cdot 48$ & $8 \cdot 61$ \\
\hline 1894 & 6.01 & 665 & 5.27 & $7 \cdot 11$ & $5 \cdot 53$ & $8 \cdot 58$ \\
\hline 1895 & 5.53 & $5 \cdot 67$ & $5 \cdot 37$ & $7 \cdot 52$ & $5 \cdot 84$ & $9 \cdot 10$ \\
\hline 1896 & $5 \cdot 50$ & 5.49 & $5 \cdot 51$ & $7 \cdot 60$ & $6 \cdot 15$ & $8 \cdot 96$ \\
\hline 1897 & $5 \cdot 47$ & $5 \cdot 51$ & $5 \cdot 42$ & $7 \cdot 83$ & $6 \cdot 34$ & $9 \cdot 23$ \\
\hline 1898 & $6 \cdot 40$ & $6 \cdot 77$ & 5.97 & $7 \cdot 98$ & 6.51 & $9 \cdot 37$ \\
\hline 1899 & $6 \cdot 24$ & $6 \cdot 85$ & $5 \cdot 55$ & $8 \cdot 25$ & $6 \cdot 70$ & $9 \cdot 70$ \\
\hline 1900 & $5 \cdot 63$ & $6 \cdot 13$ & 5.09 & 8.28 & $6 \cdot 72$ & $9 \cdot 75$ \\
\hline
\end{tabular}

From Table 1II., showing the crude cancer death-rates, it appears (1) that the registered death-rate from cancer (for persons, for males, and for females) is lower in New Zealand than in England; (2) that the registered death-rate from cancer (for persons, for males, and for females) is increasing in both countries; and (3) that the registered death-rate from cancer in New Zealand is higher for males than for females, whereas in England the female rate is the hisher.

Corrected cancer death-rates. - A crude cancer death-rate is, however, extremely fallacious, for cancer is undoubtedly a disease which affects most heavily those past middle age. and especially women. And as the New Zealand population shows a relative deficiency of adults, and especially of women, past middle life, this will of itself give to the colony deathrates from cancer which are too low when compared with those of England and Wales. Correction for age and sex distribution of the population is therefore urgently needed. This may be accomplished either by giving the death-rates from cancer at different age periods for either sex or by calculating a single corrected cancer death-rate.

\section{1.-Cancer death-rates at different age periods :-}

TABLE IV.-Showing the Annual Deathrates from Canoer per 10,000 Persons in Nen Zealand and in England and Wales.*

Mates.

\begin{tabular}{|c|c|c|c|c|c|c|}
\hline \multirow{2}{*}{ Age. } & \multicolumn{3}{|c|}{ New Zealand. } & \multicolumn{3}{|c|}{ England and Wales. } \\
\hline & $1880-84$ & $1890-94$ & 1896 & $1881-90$ & $1890-99$ & 1900 \\
\hline All ages. & - & - & $5 \cdot 49$ & $4 \cdot 30$ & $5 \cdot 81$ & $6 \cdot 72$ \\
\hline Years. & - & & & & & \\
\hline $0-5$ & - & - & 0.471 & 0.21 & 0.31 & 0.31 \\
\hline 5-15 & - & - & 0.230 & - & - & - \\
\hline $15-25$ & - & - & 0.267 & - & - & - \\
\hline $25-35$ & 0.714 & 0727 & 0.367 & 0.79 & 1.02 & L.01 \\
\hline $35-45$ & $2 \cdot 648$ & $3 \cdot 550$ & $2 \cdot 823$ & 297 & $3 \cdot 90$ & $4 \cdot 18$ \\
\hline $45-55$ & $10 \cdot 159$ & $12 \cdot 875$ & 15136 & $9 \cdot 98$ & $12 \cdot 95$ & $14: 83$ \\
\hline $55-65$ & $19 \cdot 762$ & $31 \cdot 328$ & 30.296 & $22 \cdot 99$ & $31 \cdot 30$ & $37 \cdot 96$ \\
\hline $65-75$ & $31 \cdot 680$ & $54 \cdot 439$ & $47 \cdot 530$ & 3742 & 5083 & $57 \cdot 35$ \\
\hline $75+$ & $47 \cdot 486$ & $55 \cdot 844$ & $49 \cdot 558$ & $39 \cdot 14$ & $56 \cdot 56$ & $67 \cdot 15$ \\
\hline
\end{tabular}

\begin{tabular}{c|c|c|c|c|c|c} 
All ages. & - & - & 5.51 & 7.39 & 8.88 & $9 \cdot 75$ \\
\hline $0-5$ & - & - & - & 0.19 & 0.26 & 0.29 \\
$5-15$ & - & - & 0.117 & - & - & - \\
$15-25$ & - & - & 0.133 & - & - & - \\
$25-35$ & 1.525 & 1.579 & 1.783 & 1.72 & 1.79 & 1.98 \\
$35-45$ & 6952 & 7.533 & 6.983 & 852 & $9 \cdot 18$ & 9.42 \\
$45-55$ & 18.079 & 18.098 & 18.558 & 20.42 & 23.28 & 24.33 \\
$55-65$ & 28.445 & 36.036 & 44.369 & 33.68 & 40.94 & 45.61 \\
$65-75$ & 35.782 & 45.998 & 53.458 & 45.06 & 5643 & 62.54 \\
$75+$ & 44690 & 46.051 & 30.877 & 4578 & 62.83 & 74.68 \\
\hline
\end{tabular}

* The rates for New Zealand in the years 1880-84 and 1890-94 are as given by Mr. G. Leslie, assistant actuary, New Zealand Government Life Insurance Department, in a paper on Rates of Mortality in New Zealand, published in the New Zealand Journal of Insurance, Mining, and Finance, in September and November, 1895. The rates for New Zenland in 1896 I have calculated from the returns of the RegistrarGeneral for New Zealand. The rates for England and Wales are those of the Registrar-General.

Table IV. gives results which are free from fallacies of age and sex distribution of the population, but it is convenient to express the same correction in the form of a single rate.

2. Single correoted cancer death rate. - This I have calcula ed for New Zealand during the year 1896, a census year. The population was adjusted in age and sex distribution to correspond with the composition of the English standard million for the period 1881-90; from the number thus obtained in each age group and the observed cancer deathrates for the same age groups we can estimate the number of deaths from cancer that would have occurred in New Zealand if its population had been of the sume compusition as the English standard million. The results obtained are given in Table V.:-

TABLE V.-Showing the Death rates from Cancer per 10,000 Persons in New Zealand and in England and Wales in $18: 16$.

\begin{tabular}{|c|c|c|c|c|c|c|c|c|}
\hline \multicolumn{6}{|c|}{ New Zealand. } & \multirow{2}{*}{\multicolumn{3}{|c|}{$\overbrace{\begin{array}{c}\text { Cducer dtath- } \\
\text { rates. }\end{array}}^{\text {England and Wales. }}$}} \\
\hline \multicolumn{3}{|c|}{$\begin{array}{l}\text { Crude cancer death- } \\
\text { rates. }\end{array}$} & \multicolumn{3}{|c|}{$\begin{array}{l}\text { Corrected cancer death- } \\
\text { rates. }\end{array}$} & & & \\
\hline 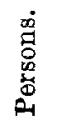 & 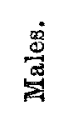 & 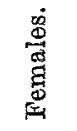 & 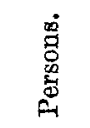 & 离 & 总 & 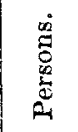 & 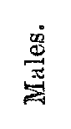 & 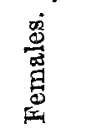 \\
\hline 5.50 & $5 \cdot 49$ & 5.51 & $6^{\circ} 67$ & 5.54 & $7 \cdot 74$ & $7 \cdot 60$ & 6.15 & $8 \cdot 96$ \\
\hline
\end{tabular}


From the corrected rates given in Table V. the following conclusions are derived : (1) The cancer death-rate in New Zealand is really higher for females than for males. This is important as correcting the fallacy of the crude rates (see Table III.) and bringing the New Zealand statistics into agreement with those of other countries. (2) The cancer death-rate is slightly lower in New Zealand than in England and Wales. There is, however, no very great difference and probably there will in the future be less still as the certification of deaths from cancer is improved. (3) The registered cancer death-rate is increasing in New Zealand as in England. Unfortunately, however, the New Zealand statistics do not afford any assistance in determining whether cancer is truly increasing or whether the apparent increase is due merely to improved diagnosis and registration.

Summary.-1. Tuberculosis in New Zealand gives a deathrate of only one-half of the English rate. This appears to be due to the relative absence in New Zealand of conditions which favour the growth and spread of this disease. 2. The death-rate of cancer, on the other hand, in New Zealand is practically equal to that in England. Hence it is probable that the conditions favourable to this disease are present to an equal extent in the two countries.

\section{Clinital allotes: \\ MEDICAL, SURGICAL, OBSTETRICAL, AND THERAPEUTICAL.}

\section{TAPEWORM AS A CAUSE OF OHOREA.}

By Joseph A. W. Pereira, L.R.O.P. Lond , M.R.C.S. Eng.

IN his "Principles and Practice of Medicine" Professor W. Osler says: "Reflex irritation was believed to play an important rôle in the disease (i.e., chorea), particularly the presence of worms or genital irritation, but I have met with no instance in which the disease could be attributed to either of these causes." He also says: "Various nervous phenomena, such as chorea, convulsions, or epilepsy, are believed to be caused by the parasites (tapeworms). Such effects, however, are very rare."

These words of Professor Osler are my excuse for publishing a case which came under my care two months ago and in which a girl, aged six years, suffering from tapeworm became the subject of an attack of chorea. The child was passing segments of the worm for two or three weeks when the first manifestations of chorea became evident. When I saw the child she was in the second grade, or the severe form of the disease, in which the movements were general and she could not talk. There was never any suspicion of rheumatism in the case and her heart remained normal throughout. A dose of filix mas dislodged the parasite and in a month's time the child was practically well. The cestode was, in my opinion, the direct exciting cause of the chorea.

Both Dr. F. T. Roberts and Dr. A. H. Carter of Birmingham mention the irritation of worms as exciting causes of chorea whilst Dr. F. Taylor and the late Dr. Edward Ellis ${ }^{1}$ are silent on the point. I believe that the occurrence of tapeworms in children under six years of age is rare, an opinion which Dr Ellis likewise expressed in his book. Professor Osler, however, says it is not uncommon.

Exeter.

\section{A NOTE ON FOUR CASES OF BLACKWATER FEVER.}

By J. Cleasby Taylor, M.D. Edin., M.R.C.S. Eng., HONORARY PHISICLAN, SEAMEN'S HOSPITAI, LAS PALMAS.

DURING the past winter four cases of this fever came under my notice. There are three points to which I wish to draw attention. 1. All these cases developed on board ship homeward bound from the west coast of Africa, presumably away from any direct or recent infection. Only one of the cases haà suffered from a previous attack. 2. In all the cases there

I A Practical Manual of the Diseases of Children. London : J. and A. Churchill. had been a slight chill (malarial), for which one gramme of quinine had been taken and within a few hours the symptoms developed. 3. The last point is the satisfactory use of boric acid, one gramme of which in hot water was given every two or three hours according to the severity of the attack. If there is vomiting it could be given by rectal or subcutaneous injection.

The following is an abstract of the clinical record of the last case. The patient, who was a French explorer, developed the characteristic symptoms at 4 A.M. On the first day, at $8.30 \mathrm{~A}$ M., his temperature was $103.8^{\circ} \mathrm{F}$. He had an icteric tinge and his urine looked like blood. At 1 P.M. his temperature was $103 \cdot 8^{\circ}$. At 5 P.M. his temperature was $101 \cdot 2^{\circ}$; the icteric tinge was less and the urine was clearer. At 9 P.M. his temperature was $101^{\circ}$. On that day he had five one-gramme (15.grain) doses of boric acid-namely, at 10 A.M., 1 P.M., 4 P.M., 7 P.M., and 11 P.M. On the second day at 4 A.M. his temperature was $99^{\circ}$. At 8 A.M. it was $99^{\circ}$; the icteric tinge was now much less and the urine was of a brownish colour. At 1 P.M. his temperature was $98.8^{\circ}$. At 8 P.M. it was $98^{\circ} 6^{\circ}$ and his urine was then clear. On this day he had three one-gramme doses of boric acidnamely, at 4 A.M., 8 A.M., and 1 P.M. After this date the patient made a satisfactory and rapid recovery. In none of the cases was any albumin found in the urine during convalescence.

Orilla del Marc, Las Palmas, Grand Canary.

\section{PURPURA (PELIOSIS) RHEUMATICA WITH STER- CORACEOUS VOMITING.}

By Joseph EDward Judson, M.R.C.S. EnG., L.R.C.P. LOND,

HOUSF SURGEON, DISTRICT INFLRMARY AND CHILDREN'S HOSPITAI, ASHTON-UNDER-LYNE.

THE patient was a male, aged 17 years, and was admitted to the District Infirmary, Ashton under-Lyne, as a supposed case of intestinal obstruction on May 3rd, 1903. He had been ill and under medical treatment for ten days with rheumatism of a subacute character and had been having only a milk diet. On the evening of May 1st he began to vomit and on the night of the 2nd the vomited matter, which had been of a bilious nature during the day, was from the description of a fæcal character.

On admission he was found to be very collapsed with a quick, thready pulse. There was no distension whatever of the abdomen, neither was there any hernia or any tenderness over the appendicular region; the liver dulness was present and there was no accumulation of fæces in the rectum. He complained of pain over the epigastric and umbilical regions. There was a marked purpuric rash over both ankles and the outer sides of the legs and also on. the forearms. The hypodermic injections of strychnine and digitalis, which were given for the collapse, were followed by a marked subcutaneous extravasation of blood. He was given sips of hot water and small quantities of milk, but vomited immediately afterwards. On the 4th, at 12.45 A. M., the vomit was large and distinctly fæcal. A glycerine enema was given at 2.30 P.M. with a slight result. At 4.30 P.M. he again vomited, but this time it was of a bilious character. Feeding by the mouth was stopped and no more vomiting: occurred; rectal feeding, however, was continued for 48. hours. The question of laparotomy was discussed but the operation was not considered justifiable. The symptoms subsided, the purpura disappeared, and the patient made a good recovery, leaving the hospital on June 23rd. I have seen him several times since and he appears to be perfectly well. There is no evidence of hysteria.

Ashton-under-Lyne.

Royal City of Dublin Hospital.-At the monthly meeting of the board of the Royal City of Dublin Hospital, held on Sept. 11th, a letter was read from Lord Plunket inclosing His Majesty's reply to the address presented on his recent visit to Ireland. The directors passed a vote of sympathy with the relatives of the late Mr. Henry Gray Croly, who had served the hospital for 40 years, and accepted the resignation with regret of Sir George F. Duffey, owing to ill-health, and placed on record its appreciation of his skilful services as visiting physician to the hospital during 21 years. 